\title{
O MANEJO DOS RESÍDUOS DOS SERVIÇOS DE SAÚDE: UM PROBLEMA A SER ENFRENTADO
}

Rafaela Gessner ${ }^{1}$, Laura Christina Macedo Piosiadlo² ${ }^{2}$ Rosa Maria Godoy Serpa da Fonseca ${ }^{3}$, Liliana Müller Larocca ${ }^{4}$

RESUMO: O gerenciamento deficiente dos Resíduos de Serviço de Saúde prejudica a saúde ambiental e populacional, além de trazer riscos de acidentes de trabalho. Este estudo tem como objetivo identificar fragilidades do processo de gerenciamento desses resíduos junto a trabalhadores que atuam em ambientes de diferentes complexidades tecnológicas. Trata-se de uma pesquisa qualitativa descritiva realizada com 29 profissionais responsáveis pelo gerenciamento dos resíduos produzidos na instituição, 20 atuantes em hospital e 9 em Unidades de Saúde da Família. Foi possível perceber que os profissionais conhecem parcialmente o manejo dos resíduos e à medida que este se afasta do serviço seu manejo é menos conhecido, constituindo mais uma evidência do processo de fragmentação do trabalho em saúde. A compreensão do manejo dos Resíduos de Serviço de Saúde pode contribuir para a diminuição de riscos de acidentes de trabalho e o impacto ambiental das ações dos serviços de saúde.

DESCRITORES: Resíduos de serviços de saúde; Gerenciamento de resíduos; Saúde do trabalhador.

\section{THE MANAGEMENT OF THE HEALTH SERVICES' WASTE: A PROBLEM TO BE FACED}

\begin{abstract}
The inadequate management of Health Service Waste is harmful to environmental and population health and brings risks of work accidents. This study aimed to identify weak points in the process of management of this waste through questioning workers who function in environments with differing technological complexity. This qualitative, descriptive research was undertaken with 29 professionals responsible for the management of the waste produced in the institution, 20 working in hospital and 9 in Family Health Centers. It was possible to perceive that the professionals are partially familiar with the management of the waste, and that as it moves away from the service, its management is less known, constituting more evidence of the process of fragmentation of work in health. Understanding the management of Health Service Waste can contribute to reducing the risk of work accidents and the environmental impact of the health services' actions.

DESCRIPTORS: Health services' waste; Waste management; Worker's health.

\section{EL MANEJO DE LOS RESIDUOS DE LOS SERVICIOS DE SALUD: UN PROBLEMA A SER AFRONTADO}

RESUMEN: La administración deficiente de los Residuos de Servicio de Salud perjudica la salud ambiental y la población, además de traer riesgos de accidentes de trabajo. Este estudio tiene como objetivo identificar fragilidades del proceso de administración de eses residuos junto a trabajadores que actuan en ambientes de diferentes complejidades tecnológicas. Es una investigación cualitativa descriptiva realizada con 29 profesionales responsables por la administración de los residuos producidos en la institución, 20 actuantes en hospital y 9 en Unidades de Salud de la Familia. Fue posible percibir que los profesionales conocen parcialmente el manejo de los residuos y que a medida que este se aleja del servicio su manejo es menos conocido, constituyendo más una evidencia del proceso de fragmentación del trabajo en salud. La comprensión del manejo de los Residuos de Servicio de Salud puede contribuir para la reducción de riesgos de accidentes de trabajo y el impacto ambiental de las acciones de los servicios de salud.

DESCRIPTORES: Residuos de servicios de salud; Administración de residuos; Salud del trabajador.

\footnotetext{
${ }^{1}$ Enfermeira. Mestranda pelo Programa de Pós-Graduação em Enfermagem da Escola de Enfermagem da Universidade de São Paulo - EE USP. Membro do Grupo de Pesquisa Gênero, Saúde e Enfermagem.

${ }^{2}$ Enfermeira. Mestre em Enfermagem. Professora do Departamento de Enfermagem da Universidade Federal do Paraná. Doutoranda pelo Programa Interunidades de Pós-Graduação em Enfermagem da EE USP. Membro do Grupo de Pesquisa Gênero, Saúde e Enfermagem. ${ }^{3}$ Enfermeira. Doutora em Enfermagem. Professora do Departamento de Enfermagem em Saúde Coletiva, do Programa Interunidades de Pós-Graduação e do Programa de Pós-Graduação em Enfermagem da EE USP. Líder do Grupo de Pesquisa Gênero, Saúde e Enfermagem. ${ }^{4}$ Enfermeira. Doutora em História. Professora do Departamento e do Programa de Pós-Graduação em Enfermagem da Universidade Federal do Paraná. Membro do Grupo de Pesquisas em Políticas, Gestão e Práticas em Saúde - GPPGPS
}

Autor correspondente:

Recebido: $18 / 07 / 2012$

Rafaela Gessner

Aprovado: 30/01/2013

Universidade de São Paulo

R. Dr. Enéas de Carvalho Aguiar, 419 - 05403-000 - São Paulo-SP-Brasil

E-mail: rgessner2@yahoo.com.br 


\section{INTRODUÇÃO}

Os Resíduos de Serviço de Saúde (RSS) são gerados em todos os serviços relacionados ao atendimento à saúde humana ou animal, inclusive serviços de assistência domiciliar e de trabalhos de campo; laboratórios analíticos de produtos para saúde; necrotérios, funerárias; serviços de medicina legal; drogarias e farmácias; estabelecimentos de ensino e pesquisa na área de saúde; centros de controle de zoonoses; importadores, distribuidores e produtores de materiais diagnósticos, dentre outros similares ${ }^{(1)}$. A grande produção desses resíduos e o gerenciamento inadequado são parte de uma problemática que traz efeitos deletérios tanto para a saúde ambiental quanto populacional ${ }^{(2)}$.

É necessário o enfrentamento desta problemática pelos profissionais da área de saúde, que devem desenvolver competências e habilidades específicas já na graduação. Trata-se de um conhecimento técnico-científico imprescindível para a formação de profissionais éticos e responsáveis, dada à amplitude das questões que envolvem a produção e o gerenciamento dos RSS.

A preocupação com manejo eficiente dos resíduos produzidos pela população vem crescendo desde a segunda metade do século XX, tendo em vista que os novos padrões de consumo resultantes da industrialização levaram ao aumento na geração de resíduos superior à capacidade de absorção da natureza ${ }^{(3)}$. Quando descartados inadequadamente, os RSS, devido a características patogênicas, como a manutenção de diferentes espécies bacterianas viáveis, podem atingir o ambiente e a saúde populacional, efeito que pode ser evitado quando de sua destinação adequada ${ }^{(4)}$. Pesquisa realizada pelo Instituto Brasileiro de Geografia e Estatística (IBGE) no período de 1989 a 2000 identificou que a população brasileira, nesse período, cresceu $16,8 \%$, enquanto a geração de resíduos cresceu $48 \%$. O mesmo estudo evidenciou que $74 \%$ dos municípios brasileiros depositavam os RSS em aterros ou lixões a céu aberto. Apenas 57\% desses separavam os RSS dos resíduos domésticos e somente $14 \%$ das prefeituras davam a eles destinação adequada ${ }^{(5)}$.

De outra parte, o desafio do tratamento dos RSS tem impulsionado a legislação e as políticas públicas para questões relacionadas à sustentabilidade do meio ambiente e preservação da saúde ${ }^{(3)}$. Atualmente no Brasil, o manejo dos RSS é regido pela Resolução da Diretoria Colegiada - RDC 306 de 07 de dezembro de $2004^{(6)}$ e pela Resolução CONAMA 358 de 29 de abril de $2005^{(1)}$.
A RDC 306/04 prevê que cada gerador de RSS elabore um Plano de Gerenciamento de Resíduos Sólidos de Saúde (PGRSS) segundo as características do produto gerado. O documento aponta e descreve as ações relativas ao manejo de resíduos sólidos, que correspondem às etapas de segregação, acondicionamento, coleta, armazenamento, transporte, tratamento e disposição final ${ }^{(6)}$. A Resolução CONAMA 358/05 dispõe sobre o tratamento e a disposição final dos RSS e prevê medidas para seu gerenciamento dos RSS com o objetivo de minimizar riscos ocupacionais no ambiente de trabalho e proteger a saúde do trabalhador e da população em geral, por meio do melhor tratamento, acondicionamento e disposição dos $\operatorname{RSS}^{(1)}$.

De acordo com a RDC 306/2004( ${ }^{(6)}$, a classificação dos RSS abrange os seguintes grupos: A - resíduos potencialmente infectantes; B - resíduos com risco químico; C - rejeitos radioativos; D - resíduos comuns e recicláveis; E - materiais perfurocortantes.

Cada grupo de RSS, de acordo com suas características, deve obedecer a um fluxo determinado de manejo correto, desde seu acondicionamento até destinação final. Resíduos provenientes do grupo A devem ser acondicionados em lixeira branca com tampa e pedal, saco branco leitoso com a identificação 'Resíduo Infectante'. Seu acondicionamento externo deve ser em um local próprio, identificado, cujo transporte deverá ser realizado de maneira especial e por profissionais capacitados. O tratamento deve ser feito por meio de autoclavação e só depois disso poderá ser depositado em aterro sanitário municipal ${ }^{(6)}$.

Os resíduos pertencentes ao grupo B devem ser acondicionados em recipientes rígidos, com tampa $\mathrm{e}$ boa vedação. Os resíduos quimioterápicos devem ser armazenados em grandes recipientes, denominados bombona. Os resíduos de mercúrio devem ser acondicionados em potes plásticos com tampa de rosca e lâmina de água para evitar a evaporação do conteúdo, devidamente identificados e datados. Demais frascos de medicamentos devem ser acondicionados em recipientes plásticos próprios. A coleta deve ser feita conforme a necessidade do local produtor; a bombona de resíduos deve ser retirada do abrigo de resíduos quando cheia, identificada e transportada. O tratamento dos resíduos químicos de laboratórios, frascos de medicamentos e de quimioterápicos deve se dar por incineração. Os materiais radioativos (grupo C), após o decaimento da radioatividade, seguem os padrões de acondicionamento das demais categorias; resíduos 
pertencentes ao grupo $\mathrm{D}$, devem ser segregados de acordo com o subgrupo a que pertencerem ${ }^{(6)}$.

Resíduos comuns devem ser armazenados em saco preto e lixeira preta identificada, e os resíduos recicláveis devem ser acondicionados em saco azul e lixeiras identificadas. Depois de coletados, os resíduos comuns e recicláveis seguem para seu destino final ou aterro municipal. Os rejeitos perfurocortantes (grupo E) devem ser acondicionados em caixa de papelão padrão $A B N T$, que deve ser utilizada até $2 / 3$ de sua capacidade e substituída a cada 24 horas, ou conforme a necessidade. $\mathrm{O}$ tratamento indicado para resíduos perfurocortantes, assim como infectantes, é a autoclavação seguida de trituração( ${ }^{(6)}$.

O gerenciamento deficiente dos RSS implica em má utilização dos materiais reaproveitáveis e em destino inadequado dos resíduos, o que eleva o risco de acidentes de trabalho, destacando-se, principalmente os artigos perfurocortantes, ligados à maior taxa de transmissão de microrganismos, em especial os vírus da Hepatite B e da Síndrome da Imunodeficiência Adquirida $^{(2)}$. Destaca-se que grande parte dos acidentes de trabalho envolvendo RSS acontece com a equipe de Enfermagem. Uma pesquisa realizada num Centro de Referência em Saúde do Trabalhador constatou que $54,4 \%$ dos acidentes com materiais perfurocortantes ocorreu com auxiliares de enfermagem ${ }^{(7)}$. A característica do trabalho da equipe de enfermagem, especialmente em hospitais, demanda uma grande proximidade física com usuários e realização de diversos procedimentos invasivos, situação que expõe os trabalhadores a infecções ${ }^{(8)}$.

A deficiência das políticas de proteção à saúde do trabalhador e no sistema de coleta e disposição final dos RSS potencializam o perigo de acidentes de trabalho ${ }^{(9)}$. Quando gerenciados inadequadamente, os RSS representam um risco para a saúde dos trabalhadores envolvidos em seu manejo, direta ou indiretamente, especialmente os materiais perfurocortantes, principais resíduos associados à transmissão de $\operatorname{agravos}^{(2)}$.

Justifica-se, portanto, a presente pesquisa cujo objetivo foi identificar as fragilidades do processo de gerenciamento de RSS (da geração ao destino final) junto a trabalhadores de saúde que atuam em ambientes de alta e baixa complexidade tecnológica. A finalidade do estudo é proporcionar subsídios que venham a melhorar o desenvolvimento de habilidades e competências específicas junto à equipe de enfermagem no que tange o gerenciamento de RSS.

\section{MÉTODO}

Trata-se de um estudo descritivo, de natureza qualitativa. Neste tipo de pesquisa, a principal marca é a descrição das propriedades ou relações existentes na comunidade ou grupo pesquisado ${ }^{(10)}$. O estudo foi realizado em 20 unidades de um hospital de alta complexidade tecnológica da cidade de Curitiba, Paraná 13 unidades de internação, três unidades ambulatoriais, três unidades de serviços e uma unidade administrativa - e em 9 Serviços de Atenção Básica (AB) constituídos por Unidades de Saúde da Família (USF) de um município da região metropolitana de Curitiba. Justifica-se a escolha das unidades hospitalares selecionadas por fornecerem uma amostra dos principais serviços existentes no hospital. O número de USF pesquisadas corresponde à totalidade de unidades existentes no município em que foi realizado este estudo.

O critério de inclusão adotado de participantes foi o profissional ser o responsável pelo gerenciamento dos RSS na unidade em que atuava. Assim, compuseram a amostra os profissionais responsáveis pelo gerenciamento dos RSS em cada uma das unidades selecionadas, totalizando 29 trabalhadores, 20 eram do hospital e 9 das USF.

A coleta dos dados se deu de 15 de julho a 3 de agosto de 2010 no hospital e de 24 de novembro a 7 de dezembro do mesmo ano nas USF por meio de uma entrevista semiestruturada, com questões a respeito do manejo dos RSS no ambiente de trabalho, dividida em quatro partes: 1) identificação do entrevistado; 2) caracterização do manejo dos resíduos produzidos (quantidade diária, armazenamento e coleta; transporte e destino final; se a segregação dos materiais é realizada na unidade, especificando as respostas de acordo com cada grupo de RSS definido na RDC 306/2004; 3) existência de programa de gerenciamento de resíduos de serviço de saúde (PGRSS); 4) ocorrência de acidentes de trabalho. Além da entrevista, foi feita a observação da identificação de resíduos nas lixeiras da unidade e o reconhecimento da existência, ou não, de equipe de ronda interna para avaliação do gerenciamento dos RSS nos locais pesquisados.

Este estudo integra o Projeto de Iniciação Científica intitulado $\mathrm{O}$ manejo dos resíduos de serviços de saúde: um problema a ser enfrentado, aprovado pelo Comitê de Ética em Pesquisa do Setor Ciências da Saúde da Universidade Federal do Paraná, sob registro n. 914.039.10.04. Após a apresentação do objetivo do estudo realizada pela pesquisadora, foi entregue aos 
participantes o Termo de Consentimento Livre e Esclarecido, contendo todas as informações necessárias e foi-lhes permitido sanar dúvidas e receber esclarecimentos quanto à liberdade de participar, ou não, do estudo, conforme a própria vontade e de acordo com os princípios da ética em pesquisa.

\section{RESULTADOS}

A categoria profissional dos trabalhadores responsáveis pelo gerenciamento de RSS está apresentada no quadro 1 .

Quadro 1 - Categoria profissional dos trabalhadores responsáveis pelo gerenciamento de Resíduos de Serviço de Saúde. Curitiba, 2010

\begin{tabular}{|l|c|}
\hline \multicolumn{2}{|c|}{ UNIDADES HOSPITALARES } \\
\hline Categoria Profissional & n \\
\hline Enfermeira & 14 \\
\hline Farmacêutico & 1 \\
\hline Nutricionista & 1 \\
\hline Responsável Técnico & 4 \\
\hline Total & 20 \\
\hline SERVIÇOS DE ATENÇ̃̃O BÁSICA \\
\hline Categoria Profissional & $\mathbf{n}$ \\
\hline Enfermeira & 9 \\
\hline Total & 9 \\
\hline
\end{tabular}

As unidades do serviço de alta complexidade tecnológica seguem, como norma para o gerenciamento dos RSS, o Procedimento Operacional Padrão (POP), desenvolvido pela comissão de gerenciamentos de resíduos do hospital, baseada na legislação vigente. Dezessete delas também elaboraram um PGRSS. Ao contrário, os serviços de atenção básica não seguem nenhum documento em vigor.

Os trabalhadores do hospital pesquisado passaram por capacitação sobre o gerenciamento de RSS no ano anterior à pesquisa. Já os trabalhadores da $\mathrm{AB}$, embora também sejam responsáveis pelo manejo desses materiais, não passaram por treinamentos acerca da temática nos anos anteriores à pesquisa.

Quanto à quantidade, os dados foram obtidos junto à coordenação do Serviço de Gerenciamento de Resíduos do hospital. Em 2009, as médias diárias de RSS produzidos, segundo os tipos foram: 47 quilos somando-se os rejeitos dos Grupos A e E e 36,6 quilos dos resíduos do Grupo B. A média mensal dos grupos C e D foram 1,2 $\mathrm{m}^{3}$ de material radioativo (grupo C) e 5,6 $\mathrm{m}^{3}$ de resíduos do grupo $\mathrm{D}$. A produção de resíduos com características infectantes totalizou aproximadamente 450 quilos/dia. Apesar da importância desse resíduo por seu risco à saúde e impacto ambiental, nos serviços de Atenção Básica não foram encontrados dados sobre produção diária e mensal dos RSS.

Quanto à segregação, armazenamento e coleta, percebeu-se que a grande preocupação dos entrevistados era separar corretamente os materiais que mais causam risco à saúde, os perfurocortantes. Em todos os locais pesquisados não foi observado descarte inadequado desses produtos. Os dados referentes ao armazenamento interno dos RSS encontram-se descritos no quadro 2. Em apenas uma unidade hospitalar produzia-se rejeitos pertencentes ao grupo $\mathrm{C}$, que eram rigorosamente separados até o total decaimento da radiação, respeitando as resoluções vigentes RDC $306 / 2004^{(6)}$ e CONAMA 358/2005(1).

Quadro 2 - Condições de armazenamento interno dos Resíduos de Serviço de Saúde de acordo com o grupo de descarte* e unidade produtora. Curitiba, 2010

\begin{tabular}{|l|l|c|c|}
\hline \multirow{2}{*}{ Grupo } & $\begin{array}{l}\text { Unidade } \\
\text { produtora }\end{array}$ & Adequado & Inadequado \\
\hline \multirow{4}{*}{ A } & Hospitalar & 19 & 1 \\
\cline { 2 - 4 } & $\begin{array}{l}\text { Atenção } \\
\text { Básica }\end{array}$ & 8 & 1 \\
\cline { 2 - 4 } & Total & 27 & 2 \\
\hline \multirow{4}{*}{ B } & Hospitalar & 15 & 5 \\
\cline { 2 - 4 } & $\begin{array}{l}\text { Atenção } \\
\text { Básica }\end{array}$ & 3 & 6 \\
\cline { 2 - 4 } & Total & 18 & 11 \\
\hline \multirow{5}{*}{ E } & Hospitalar & 16 & 4 \\
\cline { 2 - 4 } & $\begin{array}{l}\text { Atenção } \\
\text { Básica }\end{array}$ & 6 & 3 \\
\cline { 2 - 4 } & Total & 22 & 7 \\
\hline \multirow{3}{*}{} & Hospitalar & 20 & 0 \\
\cline { 2 - 4 } & $\begin{array}{l}\text { Atenção } \\
\text { Básica }\end{array}$ & 9 & 0 \\
\cline { 2 - 4 } & Total & 29 & 0 \\
\hline
\end{tabular}

Legenda *A categoria de resíduos $\mathrm{C}$ - material radioativo - não foi incluída por ser produzida apenas em uma unidade.

No serviço hospitalar, em todas as unidades pesquisadas há lixeiras identificadas para cada tipo de resíduo e um espaço específico para o armazenamento dos RSS até a coleta interna. De acordo com o POP, os resíduos infectantes, quando retirados das lixeiras, devem ser armazenados em carrinhos para o transporte. As bombonas com resíduos do grupo B ficam armazenadas em ambiente próprio até a coleta. Os materiais 
recicláveis ficam armazenados em ambiente próprio até serem encaminhados para uma área externa, onde são recolhidos. Os resíduos do grupo E são acondicionados em caixas que posteriormente são armazenadas até serem recolhidas. Ainda assim, três unidades não separavam resíduos comuns de recicláveis e três não possuíam condições adequadas para a segregação de resíduos químicos.

Nas unidades de $\mathrm{AB}$, à época da pesquisa, a separação dos rejeitos recicláveis acontecia em quatro das nove unidades investigadas. Nas demais, eram descartados junto com resíduos comuns, aumentando o volume de material encaminhado ao aterro sanitário, encarecendo o tratamento e desperdiçando materiais reaproveitáveis.

Independentemente da complexidade tecnológica do serviço, muitos profissionais não souberam descrever como é realizada a coleta de cada tipo de RSS gerado (Quadro 3). Isto aponta o desconhecimento dos trabalhadores em relação à totalidade do processo, denotando-se a fragmentação do trabalho em saúde, condição observada também quando se trata do transporte dos RSS e do seu destino final, processos desconhecidos pela maior parte dos trabalhadores.

Quadro 3- Descrição sobre como se dá a coleta interna dos RSS, de acordo com o grupo de descarte* e unidade produtora. Curitiba, 2010

\begin{tabular}{|l|l|c|c|c|c|}
\hline \multicolumn{2}{|l|}{ PROFISSIONAIS } & A & B & D & E \\
\hline \multirow{3}{*}{$\begin{array}{l}\text { Souberam } \\
\text { responder }\end{array}$} & $\begin{array}{l}\text { Unidades } \\
\text { hospitalares }\end{array}$ & 1 & 12 & 12 & 4 \\
\cline { 2 - 6 } & Atenção básica & 3 & 0 & 1 & 4 \\
\cline { 2 - 6 } & Total & 4 & 12 & 13 & 8 \\
\hline \multirow{3}{*}{$\begin{array}{l}\text { Não souberam } \\
\text { responder }\end{array}$} & $\begin{array}{l}\text { Unidades } \\
\text { hospitalares }\end{array}$ & 19 & 8 & 8 & 16 \\
\cline { 2 - 6 } & Atenção básica & 6 & 9 & 8 & 5 \\
\cline { 2 - 6 } & Total & 25 & 17 & 16 & 21 \\
\hline
\end{tabular}

Legenda *A categoria de resíduos $\mathrm{C}$ - material radioativo - não foi incluída por não ser produzida apenas em uma unidade.

No hospital pesquisado, em relação ao grupo A, 15 entrevistados citaram que o transporte interno era realizado em um container com tampa e rodízio identificado. Em quatro locais os entrevistados apenas indicaram o responsável pelo transporte desses resíduos e um informou somente quando esse serviço era realizado. Chama atenção que muitos trabalhadores responsáveis pelo gerenciamento dos RSS não sabiam como é feito o transporte intra-hospitalar dos resíduos produzidos nas unidades em que trabalhavam. Os trabalhadores da $\mathrm{AB}$ foram unânimes e relataram que o transporte externo desses artigos é uma atribuição de uma empresa terceirizada. Nenhum entrevistado soube informar como esse transporte se realiza.

A maior contradição detectada na pesquisa foi na etapa de tratamento e destino final dos RSS. Em relação aos resíduos infectantes (grupo A) apenas um entrevistado do serviço hospitalar soube precisar o tratamento e o destino adequado. Quanto aos rejeitos químicos (grupo B) um profissional do hospital e quatro de $A B$ souberam precisar o tratamento e a destinação final dados a esses produtos. Em relação aos resíduos comuns, 11 profissionais da atenção hospitalar e cinco da atenção básica (mais da metade dos 20 entrevista- dos) não sabiam que esses são encaminhados ao aterro sanitário. Quanto aos resíduos perfurocortantes, somente um profissional entrevistado (do serviço de alta complexidade) soube precisar o tratamento e o destino correto desses materiais.

\section{DISCUSSÃO}

A maior produção de RSS de um hospital são os resíduos pertencentes ao grupo A, motivo pelo qual a maior atenção em relação ao manejo correto a esse é atribuído ${ }^{(2)}$. Outro grupo de RSS fonte de maior preocupação entre os trabalhadores entrevistados foi os do Grupo E, pesquisas afirmam que esse comportamento é influenciado pelo maior risco de acidentes de trabalho com possibilidade de contaminação pessoal ${ }^{(2,11)}$.

Destaca-se que o fato da segregação entre resíduos comuns e recicláveis estar mais instituída no serviço de alta complexidade pode ser um reflexo do Decreto n 5940/06 ${ }^{(12)}$ que estabelece a coleta seletiva solidária em todos os órgãos públicos federais, obrigando-os a doar o material reciclável à cooperativas de reciclagem. Na gestão municipal responsável pelos serviços de $\mathrm{AB}$ não há norma oficial em relação ao destino dos rejeitos 
recicláveis, cabendo ao coordenador de cada unidade a decisão de como proceder.

Sabe-se que é, principalmente, na fase da coleta dos RSS que acontecem os acidentes de trabalho, sobretudo se houver segregação inadequada ${ }^{(2)}$. Este estudo demonstrou que os trabalhadores percebem o risco ao manipularem os RSS, visto que direcionam ao grupo E maior atenção. Porém esses não estão cientes dos demais acidentes que o gerenciamento ineficaz dos RSS pode provocar, bem como de sua implicação para a saúde ambiental. Por isso a importância de formar profissionais aptos ao manejo de RSS, investindo em educação continuada que englobe todas as etapas do gerenciamento dos RSS: geração, segregação, acondicionamento, coleta, tratamento e disposição final ${ }^{(13)}$.

As organizações de saúde configuram-se como instituições complexas, com projetos políticos bastante diferenciados entre si, influenciando a gestão e a organização do trabalho. A instituição hospitalar coloca-se como um amplo campo de disputas de grupos profissionais altamente qualificados e com grande autonomia de trabalho, onde ainda é forte a influência do modelo taylorista de organização do trabalho. Neste estudo percebeu-se que o conhecimento acerca do manejo dos RSS diminui à medida que o produto rejeitado se afasta do ambiente de trabalho, onde são vistos, cobrados e lembrados. Ressalta-se que o processo está dividido em operações mínimas e que os trabalhadores perdem a compreensão de sua totalidade. Dado que o tempo empregado na atividade está sob constante exame e controle, o trabalho pensante fica restrito a um pequeno grupo ${ }^{(14-15)}$.

Tudo leva a crer que os RSS são mais negligenciados à medida que saem das unidades produtoras, confirmando vários dos efeitos negativos da organização do trabalho taylorista/fordista, como a fragmentação do trabalho com evidente separação entre concepção e execução. Associada ao controle gerencial do processo e à hierarquia rígida, este tipo de organização tem levado à desmotivação e alienação de trabalhadores, bem como desequilíbrio nas cargas de trabalho. Ao não compreender o processo como um todo, o profissional ignora o risco que uma ação inadequada na fase de segregação e acondicionamento pode trazer para trabalhadores, para a saúde ambiental e para toda a coletividade em fases posteriores.

Evidencia-se, assim a necessidade de investimento em treinamento e capacitação sobre o tema abrangendo os profissionais envolvidos no processo de produção e gerenciamento de RSS.

\section{CONSIDERAÇÕES FINAIS}

$\mathrm{Na}$ atualidade, o manejo deficiente dos RSS é um problema de saúde pública, acarretando complicações tanto para a saúde ambiental como para a saúde da população. A pesquisa evidenciou que a correta segregação e o acondicionamento correto dos RSS fazem parte da rotina dos profissionais pesquisados, contudo tais profissionais não reconhecem o processo como um todo, sobretudo, das etapas que não são executadas em seus locais de trabalho.

Os serviços analisados diferem entre si quanto aos cuidados prestados e à forma de trabalho, porém, em ambos, o correto gerenciamento dos RSS precisa ser compreendido por todos os trabalhadores, não como uma tarefa menos importante, mas como etapa fundamental do trabalho produzido em equipe.

Existem dificuldades para o gerenciamento dos RSS tanto no serviço de alta complexidade tecnológica quanto nos serviços de AB. Porém, na atenção básica essa situação é mais negligenciada, o que leva a questionar se existe a ideia de que os RSS produzidos no serviço de $A B$ não são tão perigosos quanto os produzidos em um serviço de maior complexidade tecnológica. Pode-se pensar ainda que por serem produzidos em menor quantidade, não são tidos como impactantes para a saúde ambiental e coletiva.

Promover a discussão sobre o correto gerenciamento dos RSS é de extrema importância para que profissionais envolvidos com seu manejo, em especial a equipe de enfermagem, estejam conscientes do impacto negativo para a sociedade de um gerenciamento ineficaz. Esse amplia riscos de acidentes de trabalho, seja da equipe da saúde ou daqueles que darão continuidade ao processo de transporte, tratamento e descarte final dos rejeitos. Cabe também destacar a promoção de cidadania responsável no que diz respeito à relação de pessoas e instituições com o meio ambiente.

\section{REFERÊNCIAS}

1. Conselho Nacional do Meio Ambiente (CONAMA). Resolução no 358. Dispõe sobre o tratamento e a disposição final dos resíduos dos serviços de saúde e dá outras providências. Diário Oficial da República Federativa do Brasil, Brasília, 4 maio 2005.

2. Silva CE, Hoppe AE. Diagnósticos dos resíduos de serviços de saúde no interior do Rio Grande do Sul. Eng. Sanit. Ambient. 2008;10(20): 46-51.

Cogitare Enferm. 2013 Jan/Mar; 18(1):117-23 
3. Ministério da Saúde (BR). Agência Nacional de Vigilância Sanitária. Manual de gerenciamento de resíduos de serviços de saúde. Brasília: Ministério da Saúde; 2006.

4. Nascimento TC, Januzzi WA, Leonel M, Silva VL, Diniz CG. Ocorrência de bactérias clinicamente relevantes nos resíduos de serviços de saúde em um aterro sanitário brasileiro e perfil de susceptibilidade a antimicrobianos. Rev. Soc. Bras. Med. Trop. 2009;42(4):415-9.

5. Fundação Instituto Brasileiro de Geografia e Estatística. Pesquisa nacional de saneamento básico: limpeza urbana e coleta de lixo. 2000. [acesso em 20 abr 2012]. Disponível: http://www.ibge.gov.br/home/estatistica/ populacao/condicaodevida/pnsb/pnsb.pdf

6. Agência Nacional de Vigilância Sanitária (ANVISA). Resolução no306 da Agência Nacional de Vigilância Sanitária. Dispõe sobre o regulamento técnico para o gerenciamento de resíduos de serviços de saúde. Diário Oficial da República Federativa do Brasil, Brasília, 10 dez 2004.

7. Chiodi MB, Marziale MHP, Mondadori RM, Robazzi MLCC. Acidentes registrados no Centro de Referência em Saúde do Trabalhador de Ribeirão Preto, São Paulo. Rev. Gaúcha Enferm. 2010;31(2):211-7.

8. Soares LG, Labronici LM, Maftum MA, Sarquis LMM, Kirchhof AL. Risco biológico em trabalhadores de Enfermagem: promovendo a reflexão e a prevenção. Cogitare enferm. [Internet] 2011;16(2) [acesso em 4 abr 2012]. Disponível: http://ojs.c3sl.ufpr.br/ojs-2.2.4/index. php/cogitare/article/view/21815/14225

9. Bakke HN, Araújo NMC. Acidentes de trabalho com profissionais de saúde de um hospital universitário. Rev. Prod. 2010;20(4):669-76.

10. Dyniewics AM. Metodologia da pesquisa em saúde para iniciantes. $2^{\mathrm{a}}$ ed. São Caetano do Sul: Difusão; 2009.

11. Garcia LP, Ramos BG. Gerenciamento dos resíduos de serviços de saúde: uma questão de biossegurança. Cad. Saúde Pública. 2004; 20(3):744-752.

12. Ministério do Desenvolvimento Social e Combate à Fome (BR). Decreto n. 5940, de 25 de outubro de 2006: institui a separação dos resíduos recicláveis descartados pelos órgãos e entidades da administração pública federal direta e indireta, na fonte geradora, e a sua destinação às associações e cooperativas dos catadores de materiais recicláveis, e dá outras providências. Diário Oficial da União. [Internet] 26 out 2006 [acesso em
26 fev 2013]. Disponível: http://www.planalto.gov.br/ ccivil_03/_Ato2004-2006/2006/Decreto/D5940.htm

13. Corrêa LB, Lunardi VL, Santos SSC. Construção do saber sobre resíduos sólidos de serviços de saúde na formação em saúde. Rev. Gaúcha Enferm. 2008;29(4):557-64.

14. Matos E, Pires D. Teorias administrativas e organização do trabalho: de Taylor aos dias atuais, influências no setor saúde e na enfermagem. Texto Contexto-Enferm. 2006;15(3):508-14.

15. Braverman H. Trabalho e capital monopolista: a degradação do trabalho no século XX. Rio de Janeiro: Zahar; 1981. 